Conferences $>2019$ 6th International Confer...

\title{
Hourly Variation of Gaseous Attenuation at a Tropical Location in 2013
}

Publisher: IEEE

Cite This

Author(s)

I. E Ogunrinola; T.V Omotosho; S. A. Akinwumi; M.E. Emetere; W.A Ayara

View All Authors

\begin{abstract}
Document Sections

Abstract:

Electromagnetic signals are attenuated by atmospheric gases is a phenomenon that has attracted the attention of many researchers for years now. The effect of gaseous attenuation is especially significant at frequencies from $10 \mathrm{GHz}$ and above. This work investigates hourly gaseous attenuation from 10 to $50 \mathrm{GHz}$ frequency range. The hourly and diurnal impact of gaseous attenuation at Ku, Ka and V bands frequency in 2013 at Covenant University ota southwest Nigeria a tropical station has been investigated. One minute integrated time atmospheric data such as pressure, temperature and relative humidity were obtained for the location from January to December 2013 as input data to the International Telecommunications Union (ITU-676-) gaseous attenuation model was used to calculate the attenuation due to oxygen and water vapor is hereby presented.
\end{abstract}

Published in: 2019 6th International Conference on Space Science and Communication (IconSpace)

Date of Conference: $28-30$ July 2019

Date Added to IEEE Xplore: 30 December 2019

ISBN Information:

ISSN Information:

INSPEC Accession Number: 19277441

DOI: 10.1109/IconSpace.2019.8905926

Publisher: IEEE

Conference Location: Johor Bahru, Malaysia, Malaysia

\section{Introduction}

The two most effective gases involved in attenuating electromagnetic signals are oxygen and water vapour [1], [2]. The magnetic dipole moment of a gas determines the ability of that gas to attenuate electromagnetic waves. The molecules of water vapour have a magnetic dipole moment that is twice in magnitude compared to that of oxygen. By implication, water vapour in theory has a higher attenuating power compared to oxygen but in reality, the reverse is the case because the amount of oxygen in the atmosphere is far greater than that of water vapour [3], [4]. Gaseous attenuation occurs when the electric or magnetic dipole moment of gases causes them to interfere with the incoming 
electromagnetic waves of frequency in the order of the magnetic or electric dipole moment of the attenuating gas, converting the electromagnetic energy first into mechanical energy, and then to heat energy. At thermodynamic equilibrium the gas return back to its default energy state [1], [3]. The 20 to $300 \mathrm{GHz}$ range is the region where the effect of water vapour and oxygen is most significant. Below $40 \mathrm{GHz}$ the effect of oxygen is insignificant, however, it is of undeniable effect at around $50 \mathrm{GHz}$. Around $60 \mathrm{GHz}$, it becomes most significant. Attenuation due to oxygen is inversely proportional to temperature. In addition, the concentration of the absorption lines of oxygen is dependent on temperature as well as air pressure [5].

Atmospheric gas impact on fixed satellite communication link a study of its effects at $\mathrm{Ku}, \mathrm{Ka}$ and $\mathrm{V}$ bands in Nigeria

Proceeding of the 2011 IEEE International Conference on Space Science and Communication (IconSpace)

Published: 2011

Oxygen Spectroscopy Laser Sounding Instrument for Remote Sensing of Atmospheric Pressure

2008 IEEE Aerospace Conference

Published: 2008

Top Organizations with Patents on Technologies Mentioned in This Article

View More

A not-for-profit organization, IEEE is the world's largest technical professional organization dedicated to advancing technology for the benefit of humanity.

(c) Copyright 2020 IEEE - All rights reserved. Use of this web site signifies your agreement to the terms and conditions. 